\title{
S8. WHO collaboration with countries of central and eastern Europe
}

WHO COLLABORATION WITH COUNTRIES OF CENTRAL AND EASTERN EUROPE

J.G. Sampaio Faria

WHO Regional Office for Europe, Mental health, Scherfigsvej 8 , Copenhagen

With the recent political changes in countries of central and Eastern Europe, new opportunities for strengthened collaboration in the field of mental health and psychiatry have multiplied since 1990. A review of the priorities and collaborative activities developed is described and an overview of the future needs for cooperation presented.
RECENT MENTAL HEALTH POLICY DEVELOPMENT IN ESTONIA

L. Mehilane

Department of Psychiatry, University of Tartu, 18 Ülikooli Street, Tartu, EE 2400, Estonia

In Soviet times the psychiatric aid was organized in centralized way in Estonia according to the Soviet laws which considered too little our local conditions and needs. Presently mainly according to the economic difficulties the possibilities and the quality of the psychiatric aid do not correspond to our needs.

The number of psychiatric beds per 10.000 inhabitants is decreased from $14(1990)$ to $7-8$ (1993) while the number of psychiatrists has also diminished - In inpatient service to 0.6 and in outpatient service to 0.3. There are about 20 clinical psychologists in all.

At the same time the morbidity of psychic disorders is increased from 1014 (1988) to 1565 persons (1933) per 100.000 inhabitants. The number of depressive patients and their suicidality has increased (37.5 suicides per 100.000 inhabitants).

The main reorganizations in Estonia:

- the evaluation of the law of psychiatry and the conception of mental health

- reorganizing the psychiatric aid according to recently accepted law of public health care

- rearrangement of training programs for psychiatrists

- licensing psychiatric institutions

- training practical use of the ICD-10 which was taken into use in January 1994

- extensive participation in programs of international co-operation 
APPROACHES TO MENTAL HEALTH LEGISLATION

\section{Tikhonenko}

Dep. of Legal and Ethical Problems in Psychiatry, Serbsky Institute for General and Forensic Psychiatry, 23 Kropotkinsky Per., 119839 Moscow, Russia

The lack of a special legislation concerning mental health in some countries of Eastern Europe and former Sovietrepublics necessitates the drafting and approval of laws regulating psychiatric care and guaranteeing human rights in its provision. Taking into account the specificity of psychiatric practice, a higher probability of involuntary measures application in comparison with other fields of medicine, probable social consequences of psychiatric diagnosis, treatment in psychiatric establishments and connected the these protection of human rights and freedom it would be preferable to regulate these questions in a separate law about psychiatric than in general legislation about public health.

In order to overcome the established traditions of departmental norm creation it is desirable to formulate laws on psychiatric care in such a way that their norms should be of direct action and would not require turther clarification by orders, directives or instructions of public health authorities.

In our opinion laws on psychiatric care should include the following principa aspects:

1. General provisions (definitions of notions, sphere of use of the law, voluntary nature of psychiatric care, rights of persons suffering from mental disorders, representation of patients, confidentiality in the provision of psychiatric care informed consent to treatment and right to refuse treatment.

2. Provision of psychiatric care and social protection of persons suffering from mental disorders.

3. Institutions and persons providing psychiatric care.

4. Forms of psychiatric care and procedures of its provision (psychiatric evaluation outpatients care, "dispensary observation, admission to a mental hospital, ground and procedure of the involuntary hospitalization and order of the court hearing) 5. Control and public prosecutor supervision. Appeals and liability for the violation at a law.

Above mentioned approaches have been realized in the "Law of the Russican Federation on Psychiatric Care and Guarantees of Citzens' Rights in its provision (1933).
POSTGRADUATE TRAINING IN PSYCHIATRY

P. Macrea

Department of Psychiatry, University of Medicine, Cluj-Napoca, Romania

Romania is now in a difficult period of transition and it strives toward regaining its place in the European community.

The actual postgraduate training programm for psychiatry is based on an inter-disciplinary approach.

The novelty of the last years refers to the adoption of the 5 years residency system.

The practical training activities focus primarily in clinical psychiatry (nosology, diagnosis, treatment), but also gives attention to developmenta psychology, primary health care and specialised fields such as psychotherapy, psychotherapy and community psychiatry.

A better access to information is possible for the residents (with the help of WHO) and a better training especially in psychotherapies (psychodrama group Balint psychoanalysis) with intemational diplomas. 